\title{
What motivates informal caregivers of people with dementia (PWD): a qualitative study
}

\author{
Shakiba Zahed ${ }^{1} \mathbb{D}$, Maryam Emami ${ }^{2}$, Shahrzad Bazargan-Hejazi ${ }^{3}$, Ahmad Ali Eslami ${ }^{4}$, Majid Barekatain ${ }^{5}$ and \\ Fereshteh Zamani-Alavijeh ${ }^{*^{*}}$ (1)
}

\begin{abstract}
Background: The burden of caring for People with Dementia (PWD) is heavy; identifying incentives that motivate them in providing care is essential in facilitating and optimizing care. This study aims to explore and describe these motivating factors.

Methods: We conducted this qualitative study between January 2016 and January 2017 in Isfahan, Iran. Data were extracted through in-depth, semi-structured interviews with 19 caregivers of PWD. These data were then examined through thematic content analysis.

Results: We identified four categories of psychological motives based on the caregivers' feedback and experience. These include 1) Moral-based motives, 2) Religious, and spiritual motives; 3) Financial motives, and 4) Wicked motives.

Conclusions: Our results revealed several aspects of caregivers' motives. They include moral, religious, and spiritual aspects; sharing housing accommodations, and the likelihood of inheriting a portion of the patient's assets based on unspoken rules and informal arrangements in the family, and wicked and immoral aspects. These findings can inform future efforts in enhancing the experiences of caregivers of PWD, and subsequently, the quality of care these patients receive. It further suggests that family members, members of a religious and spiritual organization, as well as social media, could play important roles in setting the stage.
\end{abstract}

Keywords: Alzheimer's disease and other dementias, Caregivers, Motivation, Religious, And spiritual motivators

\section{Background}

Globally, 47.5 million people were diagnosed with dementia in 2015, and this figure is expected to reach 75.6 million in 2030, and over 135 million by 2050 [1]. This implies globally 7.7 million new cases or one new case every 4 seconds requires care and attention from the system, family members, or other sources, thus, challenging the financial, physical, and psychological resources in the countries including in Iran $[2,3]$.

With the higher prevalence of People with Dementia (PWD), identifying a source of regular caregiving for PWD has become a routine practice in Iran and other

\footnotetext{
* Correspondence: fe.zamani@gmail.com; fe.zamani@hlth.mui.ac.ir

${ }^{6}$ Department of Health Education and Promotion, School of Health, Isfahan University of Medical Sciences, Isfahan, Iran

Full list of author information is available at the end of the article
}

countries [2, 4-6]. Family members (informal caregivers), often assume this responsibility and serve as an interface between the PWD and health services [7, 8]. However, the responsibility of caregiving is also taken up by formal caregivers who often are paid for their services [9]. It is reported that informal caregivers are more likely motivated by emotional ties, cultural, spiritual, and religious responsibilities [2], while financial incentives motivate the formal caregivers [9].

Nevertheless, it is reported that the caregivers' motivations influence their subjective experience of this role and, consequently the patterns of caregiving behavior [10-13]. Having higher positive intrinsic motivations have been associated with positive, meaningful caregiving experiences $[11,13-15]$, and consequently associated with higher quality care outcomes for the care receivers [16].

(c) The Author(s). 2019 Open Access This article is distributed under the terms of the Creative Commons Attribution 4.0 International License (http://creativecommons.org/licenses/by/4.0/), which permits unrestricted use, distribution, and 
Formal and informal caregivers play an essential role in the provision of care for PWD. Exploring their perspectives on what motivates them to perform their responsibilities fully elucidates approaches to support them in providing optimal care [7, 17].

However, many of the caregivers' beliefs, perceptions, and experiences are difficult to quantify [18] because they are influenced by a varying degree of socio-cultural and traditional values, which may deeply influence the individual's subjective perception of these values $[2,18]$. This is especially the case in a country such as Iran, where tradition, custom, and religious faith dominates virtually every facet of caregiving $[2,18]$.

In this study, we attempt to answer the following research question; what are the informal caregiver's motives for taking up this role? We aim to explore and describe these motives. Once we better understand the caregivers' motives for caring for the PWD, we can develop/tailor interventions to protect the caregivers' altruistic motivation and diminish negative aspects of informal caregiving [19].

\section{Methods}

\section{Study design, setting, and recruitment}

We adopted a qualitative exploratory research approach. This approach can help to explore and better understand the process of engaging in a behavior and experiencing it from the perspective of the participant [20-22].

The study was conducted in Isfahan, Iran, between January 2016 and February 2017. Recruitment sites include the patient's home and physician offices. We used convenient purposive sampling, and a nonprobability method used when researchers seek participants with specific characteristics that set them apart from others (for example husbands/wives, daughters/ sons/ granddaughters/grandsons, friends, relatives, or no relationship) [23]. We also considered data saturation as a point of "diminishing returns" in a qualitative sample, whereby no new or relevant information emerges, or when the addition of more data does not add to the information already collected. Following these methods in qualitative studies allows for richer analytic generalizations [14, 24].

Female and male informal caregivers, 18 years of age and older who had at least 6 months of caregiving experience with PWD were eligible to participate in the study. This was determined by the study investigators (SZ), who subsequently enrolled 19 participants in the study and obtained informed consent.

\section{Data collection}

Based on the prior arrangements with participants, the 19 in-depth, semi-structured interviews were conducted in Farsi (the predominant and official language in Iran) by one of the trained investigators (SZ) at different locations, chosen by the participant. The interviewer used an interview guide, which was developed for the purpose of this study. To build rapport with the participants, the interviewer (SZ) initiated the interview with small talks that were engaging and make the participants feel comfortable, respected, and feeling that the interviewer thinks along the same lines as them. To align the study questions with the study aim, we asked participants to explain, in detail, their motives for providing care to PWD. We also used several probing questions to delineate more specific and detailed answers. Each interview lasted between 45 to $60 \mathrm{~min}$. In addition, we collected several basic demographic information to describe the study sample characteristics (Additional file 1).

\section{Data analysis}

The interviews were recorded and subsequently transcribed verbatim in Farsi. The qualitative data were concurrently organized and analyzed using inductive content analysis [25, 26], in which theory is derived from data and then demonstrated by characteristic examples of data [21]. We used "Coding Consensus, Co-occurrence, and Comparison" methodology [27], which involved reviewers (SZ, ME) independently reading and rereading the initial verbatim transcript, identifying key sub-themes according to the participants' phrases, and performing initial coding. Subsequently, another member of the research team (FZA) randomly selected sections of the transcripts and independently followed the same methodology to verify identified codes, and resolve any thematic issues. This approach is recommended in qualitative research to enhance the verifiability of the data analysis $[28,29]$. The final codes were then categorized according to their similarities and differences [30, 31].

\section{Trustworthiness}

To ensure that the nuances of data are reflected in coding, different members of our research team scrutinized and evaluated the transcripts, codes, and categories. In addition, we followed the recommended and accepted methodology and relied on the qualifications and expertise of an experienced, multidisciplinary research team to collect rich data and conduct reliable analysis [25, 28, 31, 32]. The team included an experienced investigator with an extensive background in qualitative study and health education (FZA, $\mathrm{SBH}$ ), two health educators (SZ and $\mathrm{AE}$ ), and two psychiatrists (ME and $M B)$. Furthermore, for publication purposes, SZ and FZA translated the quotes to English, and their translation was back-translated by SHB to ensure accuracy.

\section{Results}

Participants consisted of 16 women and three men (total, $n=19)$ who were the informal caregivers of PWD. All the 
informal caregivers were among friends, wives, daughters, sons, husbands, daughters-in-law, and nieces, or nephews of PWD. Participants ranged in age from 23 to 84, with a mean age of $51.89 \pm 5.62$ years. The majority were married (About $84 \%)$ and literate (88\%), (Table 1). None of the informal caregivers had received training regarding caring for PWD.

We identified four categories of psychosocial motives based on informal caregivers' feedback and experiences. These include in the order of presentation 1) Moral-based motives, 2) Religious, and spiritual motives; 3) Financial motives, and 4) Wicked motives (Table 2).

\section{Moral-based motives}

Satisfying one's moral principle and sense of commitment and compassion to the family

Children of the PWD, who served as the informal caregivers, considered taking care of their parents an honorable duty and believed that they were morally obligated to take care of them in old age, regardless of their health

Table 1 Sociodemographic characteristics of participants

\begin{tabular}{|c|c|c|}
\hline \multirow[b]{2}{*}{ Variable } & \multicolumn{2}{|l|}{ Caregivers $(n=19)$} \\
\hline & Number of Respondents & Percentages \\
\hline \multicolumn{3}{|l|}{ Sex } \\
\hline Female & 16 & 84.2 \\
\hline Male & 3 & 15.8 \\
\hline \multicolumn{3}{|l|}{ Age (years) } \\
\hline $18-27$ & 1 & 5.3 \\
\hline $28-37$ & 2 & 10.5 \\
\hline $38-47$ & 4 & 21.1 \\
\hline $48-57$ & 7 & 36.8 \\
\hline $58-67$ & 3 & 15.8 \\
\hline$>68$ & 2 & 10.5 \\
\hline \multicolumn{3}{|l|}{ Marital status } \\
\hline Married & 16 & 84.2 \\
\hline Single & 3 & 15.8 \\
\hline \multicolumn{3}{|l|}{ Education Level } \\
\hline No formal education & 2 & 10.5 \\
\hline Less than 12 years & 2 & 10.5 \\
\hline High School Diploma & 8 & 42.1 \\
\hline Some University/Graduate & 7 & 36.9 \\
\hline \multicolumn{3}{|l|}{ Relationship to patient } \\
\hline Wife & 4 & 21.1 \\
\hline Daughter & 9 & 47.4 \\
\hline Son & 1 & 5.2 \\
\hline husband & 1 & 5.2 \\
\hline Nephew and Niece & 1 & 5.2 \\
\hline Daughter-in-law & 2 & 10.5 \\
\hline Neighbor and or Friend & 1 & 5.2 \\
\hline
\end{tabular}

status. A 40-60-year-old participant stated, "Besides the inner satisfaction and contentment that taking care of my mother gives me, I consider it my moral duty to serve my mother."

Several spouses of the PWD considered taking care of their husbands or wives a way of acknowledging their commitment to a lifelong love and care they shared as couples. One caregiver said: "For our love and for a lifetime of romantic life together (crying), I am committed to taking care of my spouse." Another informal caregiver put it this way: "It is hard, I feel like I have lost my romantic and relational partner, but I do not get mad or resent this situation. I feel lonely. It is like someone has tightened one of your hands behind you and from now on you have to go along with life only with one hand. But when we married, we pledged to a lifelong commitment to each other. Only someone who is in my position could fully understand what I mean."

A caregiver of a PWD expressed: "My grandmother cultivated compassion and empathy in our family by way of taking care of my grandfather, despite her old age. In a way, she cared about him more than herself. This is a reason my siblings and I share taking care of our mother. This is our way of showing our commitment to the values that were nurtured in our family.

An informal caregiver mentioned that "My husband's mental health has been deteriorating. I was offered to place him in a nursing facility/home. I decided against it. Although I'm old and it's difficult for me to take care of him, but I think he is safer and happier at home. This is the least I can do (... He is still the love of my life.) ". This feeling of giving of oneself to facilitate the well-being of a patient was common among family members who cared for PWD.

\section{Nurturing devotion and selflessness}

According to one of the caregivers, the thought of getting diagnosed with 'Alzheimer's is a troubling thought that comes to mind as one gets older and requires dedication and selflessness from the side of the family. Following is part of her statement: "I have a toxic in-law. She is very self-centered, spiteful, stubborn, and controlling. It is easy for her to hurt whoever gets close to her. Her children are annoyed with her and do not want to stay and take care of her. But my approach is to nurture dedication and selflessness in my children. My husband and I, along with our children, visit her almost every day. I cook, feed, and bathe her. Children help with cleaning the house, and my husband helps with shopping and grocery. Hopefully, I can nurture the spirit of selflessness in my children."

\section{Religious and spiritual motives}

Adherence to religious beliefs and inscription

Several other caregivers mentioned obeying God's commands as reflected in the Quran (Muslim Holy Book) 
Table 2 The caregivers' motives for caring for the PWD

\begin{tabular}{ll}
\hline Main Categories & Subcategory \\
\hline 1. Moral-Based Motives & $\begin{array}{l}\text { 1.1. Satiffying one's moral principle and sense of commitment and compassion to the family } \\
\text { 2. Religious and Spiritual Motives }\end{array}$ \\
& $\begin{array}{l}\text { 1.2. Nurturing devotion and selflessness } \\
\text { 2.1. Adherence to religious beliefs and inscription } \\
\text { 2.2. To receive spiritual or divine reward }\end{array}$ \\
$\begin{array}{ll}\text { 2.3. To avoid divine punishment } \\
\text { 2.4. Other religious beliefs and associations }\end{array}$ \\
$\begin{array}{ll}\text { 3.1. Attaining living accommodations } \\
\text { 3.2. Gaining inheritance entitlement }\end{array}$ \\
$\begin{array}{ll}\text { 4.1. Getting revenge } \\
\text { 4.2. Stealing }\end{array}$
\end{tabular}

inscriptions as the main reason they took care of a family PWD. One middle-aged caregiver said, "This disease has been mentioned in Surah Al-Hajj, verse 5, and there are also verses in the Quran about the need to take care of parents in old age or generally older people." (Surah Al-Isra, verses 23 and 24).

\section{To receive spiritual or divine reward}

The participants believed that they would be spiritually rewarded for the honest care they provide to PWD. One participant articulated this notion as the following: "I have noticed how serving my mother has positively affected my life. I had a bad car accident a while back. From the look of my car, everybody thought the driver must have been dead. After the accident, I experienced numbness and tingling in my spine, indicating the possibility of becoming paralyzed. However, as you see, I am OK. I truly believe it was my mother's prayers that helped me to recover." (A 30-40-year-old caregiver).

\section{To avoid divine punishment}

The motivation for salvation from divine retribution was also one of the factors associated with caring for sick family members. One participant said: "My father was diagnosed with Alzheimer's last year. His behavior does no longer resembles the kind man he was. It is hurtful the way he treats us. But we take care of him in spite of this. We believe God observes will condemn us if we do not take care of him. The scriptures in the Quran inspires the worshippers to be kind and compassionate to the sick." (A middle-aged caregiver).

\section{Other religious beliefs and associations}

For some participants, certain religious beliefs and associations provided the incentive and motivation for caring for an older adult with Alzheimer's. A middle-aged caregiver explained that "My mother and I are taking care of a patient who has Alzheimer's disease because she is a descendant of the Prophet Mohammad (a Saadat). In
Muslin religion it is considered as an honor to serve Prophet Mohammad descendants .... It probably would have been different if she was not a Saadat. We serve this patient wholeheartedly."

\section{Financial motives \\ Attaining living accommodations}

The need for a place to live was another motivating factor. "... my husband was.sick. We spent everything we had to take care of his needs, but he died two years ago. Since my baby and I didn't have a place to live, we moved to one of my relatives' house. She has Alzheimer's disease. On days, when her daughter is at work, I take care of her. I am satisfied, and they are appreciative. Her house is big, and I have a room for myself and my baby. I don't have to look for a place to live. It would have been challenging with a baby". (A young caregiver).

\section{Gaining inheritance entitlement}

Sometimes family members of the Alzheimer's patient informally and in private arrangements offer a share of the patient's inheritance to the caregiver as an incentive. This unspoken rule is motivating, as stated by the following participant: "My mother was diagnosed with Alzheimer's disease nearly three years ago. At that time, my sister and brother lived out of the state and couldn't provide care for her. Instead, they offered me my mother's estate, which was her only asset. They motivated me to live with my mother and take care of her by way of waving their share of the inheritance. My mother is dear to all of us, but they cannot live here. It comforted them when I accepted the offer. They come to see my mother two or three times a year." (An over forty years old caregiver).

\section{Wicked motives \\ Getting revenge}

Of the participants, we found those who aimed to settle their hostility to the family at the expense of the care receiver's' health. A caregiver explained, "I have been living 
with my husband's family for years, and I've been hurt a lot by them. I forgave them for the sake of my children. But now they are making me to take care of my fatherin-law. It is not fair that they have put me in this position. He has Alzheimer's. So I just make sure he is fed well. That is all. Other needs, I neglect. This is my way of getting revenge for my in-law's abusive behaviors towards me, and my family." (An over forty years old caregiver).

\section{Stealing}

A caregiver of an Alzheimer's patient stated that my father's family is looking for an opportunity to take monetary advantage of his situation. This participant explained: "Knowing of my father's dementia, a couple of relatives came to our house to help by way of taking him out to a park. However, later on, I found out that they had taken him to a public notary and made him sign away some of his properties in their name. I tried hard to prove that my sick father was incapable of making such decisions. Just recently, finally, I was able to prove their crime through legal action." (An adult caregiver).

\section{Discussion}

In this qualitative study, the general underlying motives of the informal caregivers of PWD were: 1) Following a moral principle and nurturing them; 2) Having respect for religious scripture, and obeying one's religious and spiritual beliefs; 3) Gaining financial advantage, and 4) Bing mean and immoral.

Perceiving that caring for PWD is morally justified, and religiously and spiritually fulfilling, aligns with the Iranian tradition and Islamic belief [2]. It encourages family support, respect for the elders, and altruistic respect for patients, which is ultimately self-satisfying [33, 34]. Religiosity has been linked to having an agreeable and conscientious attribute [35]. It has been suggested that having a satisfying experience with caregiving responsibilities reduces caregiver stress, helps with coping [36], and enhances the quality of care [37]. In Iran, PWD, often, is cared for by their wives and/or daughters [38]. Motivated morally, religiously, and spiritually, they are poised to provide ideal care for these individuals, one that is based on a loving, kind, and understanding attitude, commitment, compassion, and kindness toward the care receiver $[15,39,40]$.

A few informal caregivers expressed pecuniary incentives as a means to reinforce and boost their motivation in providing care for a PWD. However, not the primary motivation. As reported in the previous studies, employment and financial gain are significant motivators for formal caregivers in caring for PWD [6, 41-43].

The finding that a few participants were also driven by an inner desire to financially abuse the caregiving situation, points to the need for strategies that safeguard PWD against susceptibility to financial exploitation. In a previous study, of a total of 125 elderly who were interviewed, $9.6 \%$ reported experiencing abuse including neglect, physical or financial abuse. However, elderly patients are reluctant to report abuse [44]. In cases where providing care by an informal caregiver is the option, the level of safeguard could be aligned with the patient's level of vulnerability, nature of relationship between the caregiver and the care receiver, benefits gained by the caregiver, and the level of influence the caregiver has on the care receiver to commit wrongdoing [45]. Several screening tools are available to identify caregivers' wrongdoings, but more research is needed to establish their validity and applications for caregivers of PWD [46, 47].

\section{Study limitations}

Our results have limited reproducibility since this is a qualitative study, but offer some insights into the research that can be built upon in further studies. Other controversies around qualitative studies have to do with the trustworthiness of results [48]. We have considered the following to enhance the trustworthiness of our findings. We utilized different types of informal caregivers to capture different views and experiences of the participating caregivers. We performed a rigorous data collection and comprehensive data analysis to support data saturation and robust reports of data. And, we corroborated the results by using multiple reviewers to ensure that participants' viewpoints were adequately interpreted. Nonetheless, the extent to which our findings could be generalized to other cultures, especially those which are secular, needs further investigation.

\section{Conclusions}

Our results identified several aspects of motivation for providing care to PWD by the informal caregiver. They include moral, religious, and spiritual aspects; sharing housing accommodations, and the likelihood of inheriting a portion of the patient's assets based on unspoken rules and informal arrangements in the family, and wicked and immoral aspects. These findings can inform future investigators who aim to enhance the experiences of informal caregivers of PWD, and subsequently, the quality of the care they provide. It is also important to study how caregivers' motivations change as their responsibilities evolve. Moreover, exploratory research into factors, structures, and processes through which informal caregivers can provide optimal care to PWD should be encouraged and supported. 


\section{Supplementary information}

Supplementary information accompanies this paper at https://doi.org/10. 1186/s12904-019-0491-9.

Additional file 1. Study demographic questionnaire.

\section{Abbreviations}

PWD: People with Dementia

\section{Acknowledgments}

The authors wish to express their gratitude to Isfahan University of Medical Sciences for funding this project, and to the patients, their families and informal caregivers, for their cooperation and help in conducting this study.

\section{Authors' contributions}

-SZ. PhD, is responsible for the collection of data, critical review of data, the concept of the paper, the review of the literature, the interpretation and discussion of the results, and writing the article. ME, MD., is responsible for the critical review of the manuscript, the interpretation of the results, and the concept of the paper. SBH, PhD., is responsible for the critical review of data, interpretation of the results, manuscript content, revisions, and final submission. AAE, PhD., is responsible for the supervision of the collection of data, the critical review of the manuscript, and the interpretation of the results. $M B, M D$., is responsible for the critical review of the manuscript, the interpretation of the results, the concept of the paper, and the critical review of the manuscript. FZA, PhD., is responsible for the supervision of the collection of data, the concept and development of the paper, and the interpretation and discussion of the results. All authors have read and approved the manuscript.

\section{Funding}

This work was supported in part by grants from the Student Research Center, School of Health, Isfahan University of Medical Sciences, Isfahan, Iran. This funding mechanism supports student research implementation i.e., data collection, translation, and data analysis. The project was registered under the ID [number395204]'.

\section{Availability of data and materials}

Data used for this manuscript will be available upon reasonable request (i.e., no personal identifying information can be shared) by the corresponding author of this manuscript.

\section{Ethics approval and consent to participate}

All participants provided written informed consent, where they were informed of the voluntary nature of participation and the participant's right to stop participation at any time. The study was approved by the research ethics committee of Isfahan University School of Medicine.

\section{Consent for publication}

Not Applicable.

\section{Competing interests}

The authors declare that they have no competing interests.

\section{Author details}

${ }^{1}$ Candidate in Health Education and Health Promotion, Student Research Committee, School of Health, Isfahan University of Medical Sciences, Isfahan, Iran. ${ }^{2}$ Department of Psychiatry, School of Medicine, Isfahan University of Medical Sciences, Isfahan, Iran. ${ }^{3}$ Department of Psychiatry, College of Medicine, Charles Drew University of Medicine and Science, and David Geffen School of Medicine, the University of California at Los Angeles (UCLA), Los Angeles, USA. ${ }^{4}$ Department of Health Education and Promotion, School of Health, Isfahan University of Medical Sciences, Isfahan, Iran. ${ }^{5}$ Department of Psychiatry, School of Medicine, Isfahan University of Medical Sciences, Isfahan, Iran. ${ }^{6}$ Department of Health Education and Promotion, School of Health, Isfahan University of Medical Sciences, Isfahan, Iran.
Received: 15 January 2019 Accepted: 18 November 2019

Published online: 28 November 2019

\section{References}

1. Organization WH. Dementia: a public health priority: World Health Organization; 2012.

2. Abdollahpour I, Noroozian M, Nedjat S, Majdzadeh R. Caregiver burden and its determinants among the family members of patients with dementia in Iran. Int J Prev Med. 2012;3(8):544-51.

3. Demential: A Public Health Priority 2013 [Available from: http://www.who. int/mental health/neurology/dementia/en/

4. Schulz R, Martire LM. Family caregiving of persons with dementia: prevalence, health effects, and support strategies. Am J Geriatr Psychiatry. 2004;12(3):240-9.

5. Akbari M, Alavi M, Irajpour A, JJljon M. Challenges of family caregivers of patients with mental disorders in Iran: A narrative review. Iran J Nurs Midwifery Res. 2018;23(5):329 research m.

6. Shinan-Altman S, Riabzev A, Ayalon L. Mixed motivations to provide formal care to older adults: lessons from a training program. Int Psychogeriatr. 2019:31(3):341-9.

7. Cova I, Travi N, Maggiore L, Cucumo V, Mariani C, Pomati S. What are the caregivers' needs on dementia care? An integrated qualitative and quantitative assessment. Neurol Sci. 2018;39(6):1085-91.

8. Alliance FC. Fact sheet: selected caregiver statistics. San Francisco: Family Caregiver Alliance; 2012

9. Herbert $\mathrm{C}$, Molinsky JH. What can be done to better support older adults to age successfully in their homes and communities? Health Aff. 2019;38(5): 860-4.

10. Quinn C, Clare L, Woods RT. Balancing needs: The role of motivations, meanings and relationship dynamics in the experience of informal caregivers of people with dementia. Dementia (London). 2015;14(2):220-37.

11. Quinn C, Clare L, McGuinness T, Woods RT. The impact of relationships, motivations, and meanings on dementia caregiving outcomes. Int Psychogeriatr. 2012;24(11):1816-26

12. Andren S, Elmstahl S. Family caregivers' subjective experiences of satisfaction in dementia care: aspects of burden, subjective health and sense of coherence. Scand J Caring Sci. 2005:19(2):157-68.

13. Feeney BC, Collins NL. Motivations for caregiving in adult intimate relationships: influences on caregiving behavior and relationship functioning. Personal Soc Psychol Bull. 2003;29(8):950-68.

14. Morse JM. The significance of saturation. Qual Health Res. 1995;5:147-9.

15. Quinn C, Clare L, Woods RT. What predicts whether caregivers of people with dementia find meaning in their role? Int J Geriatr Psychiatry. 2012; 27(11):1195-202

16. Moore KJ, Davis S, Gola A, Harrington J, Kupeli N, Vickerstaff V, et al. Experiences of end of life amongst family carers of people with advanced dementia: longitudinal cohort study with mixed methods. BMC Geriatr. 2017:17(1):135.

17. Quinn C, Clare L, Woods RT. The impact of motivations and meanings on the wellbeing of caregivers of people with dementia: a systematic review. Int Psychogeriatr. 2010;22(1):43-55.

18. Yektatalab S, Sharif F, Kaveh MH, Khoshknab MF, Petramfar P. Living with and caring for patients with Alzheimer's disease in nursing homes. J Caring Sci. 2013;2(3):187.

19. Mittelman MS, Roth DL, Haley WE, Zarit SH. Effects of a caregiver intervention on negative caregiver appraisals of behavior problems in patients with Alzheimer's disease: results of a randomized trial. J Gerontol Ser B Psychol Sci Soc Sci. 2004;59(1):27-34.

20. Merriam SB, Tisdell EJ. Qualitative research: a guide to design and implementation. San Francisco: Wiley; 2015.

21. Glaser BG, Strauss AL. Discovery of grounded theory: strategies for qualitative research: Routledge; 2017.

22. Bazargan-Hejazi S, Zamani-Alavijeh F, Hindman D, Mohamadi E, Bazargan M How do motorcyclists manage mental tensions of risky riding? BMC Public Health. 2013;13:865.

23. Flick U. An introduction to qualitative research: theory, method and applications. London: Sage; 1998.

24. Polit D, Hungler B. Essentials of nursing research: methods, appraisal, asid utilization; 1994

25. Elo S, Kyngäs H. The qualitative content analysis process. J Adv Nurs. 2008; 62(1):107-15. 
26. Hsieh H-F, Shannon SE. Three approaches to qualitative content analysis. Qual Health Res. 2005;15(9):1277-88.

27. Willms DG, Best JA, Taylor DW, Gilbert JR, Wilson DM, Lindsay EA, et al. A systematic approach for using qualitative methods in primary prevention research. Med Anthropol Q. 1990;4(4):391-409.

28. Patton MQ. Qualitative Research \& Evaluation Methods. Thousand Oaks: Sage; 2002.

29. Malterud K. Qualitative research: standards, challenges, and guidelines. Lancet. 2001;358(9280):483-8.

30. Priest $H$, Roberts $P$, Woods $L$. An overview of three different approaches to the interpretation of qualitative data. Part 1: theoretical issues. Nurs Res. 2002;10(1):30-42.

31. Polit D, Beck CT. Essentials of nursing research: methods, appraisal, and utilization. 6th ed: Lippincott Williams \& Wilkins; 2006.

32. Shenton AK. Strategies for ensuring trustworthiness in qualitative research projects. Educ Inf. 2004;22(2):63-75.

33. Moeini B, Barati M, Farhadian M, Ara MH. The association between social support and happiness among elderly in Iran. Korean J Fam Med. 2018; 39(4):260.

34. Dai B, Mao Z, Wu B, Mei YJ, Levkoff S, Wang H. Family caregiver's perception of alzheimer's disease and caregiving in chinese culture. Soc Work Public Health. 2015:30(2):185-96.

35. Saroglou V. Religion and the five factors of personality: a meta-analytic review. Personal Individ Differ. 2002;32(1):15-25.

36. Stolley JM, Buckwalter KC, Koenig HG. Prayer and religious coping for caregivers of persons with Alzheimer's disease and related disorders. Am J Alzheimers Dis. 1999;14(3):181-91.

37. Hodge DR, Sun F. Positive feelings of caregiving among Latino Alzheimer's family caregivers: understanding the role of spirituality. Aging Ment Health. 2012;16(6):689-98.

38. Mazloomi Mahmoodabad SS, Zahed S, Emami M, Barekatain M, Shahnazi H, Mahaki B. A Study on the Evaluation of Relationship between the Predisposing Factors and Practice and Demographic Variables in Caregivers of Patients with Alzheimer's Diseases. J Isfahan Med Sch. 2015;33(329):429-41.

39. Monin JK, Schulz R, Feeney BC. Compassionate love in individuals with Alzheimer's disease and their spousal caregivers: associations with caregivers' psychological health. The Gerontologist. 2014;55(6):981-9.

40. Hsieh W, Chen Q, Sun Q, Chen P, Chen Y, Xu W, et al. Looking for positive viewpoints for Alzheimer's caregivers: Case evaluation of a positive energy group 临床转化神经科学 2016;2(1):65-70

41. Mousavi SH, Dargahi H. Ethnic differences and motivation based on Maslow's theory on Iranian employees. Iran J Public Health. 2013;42(5):516.

42. Reid RA. Improving the experiences of informal and formal Alzheimer's disease and dementias caregivers: Walden University; 2015.

43. Gibson AK, Anderson KA, Acocks S. Exploring the service and support needs of families with early-onset Alzheimer's disease. Am J Alzheimers Dis Other Dement. 2014;29(7):596-600.

44. Kumar P, Patra S. A study on elder abuse in an urban resettlement colony of Delhi. J Family Med Prim Care. 2019;8(2):621-5.

45. Wilber KH, Reynolds SL. Introducing a framework for defining financial abuse of the elderly. J Elder Abuse Negl. 1997;8(2):61-80.

46. Cohen M. Screening tools for the identification of elder abuse. JCOM. 2011; 18(6):261-70.

47. Melchiorre MG, Di Rosa M, Barbabella F, Barbini N, Lattanzio F, Chiatti C Validation of the Italian version of the caregiver abuse screen among family caregivers of older people with Alzheimer's disease. Biomed Res Int. 2017; 2017:3458372

48. Giacomini MKCD. For the Evidence-Based Medicine Working, Group Users' Guides to the Medical Literature: XXIII. Qualitative Research in Health Care A. Are the Results of the Study Valid? 2000. p. 357-62.

\section{Publisher's Note}

Springer Nature remains neutral with regard to jurisdictional claims in published maps and institutional affiliations.

Ready to submit your research? Choose BMC and benefit from:

- fast, convenient online submission

- thorough peer review by experienced researchers in your field

- rapid publication on acceptance

- support for research data, including large and complex data types

- gold Open Access which fosters wider collaboration and increased citations

- maximum visibility for your research: over $100 \mathrm{M}$ website views per year

At BMC, research is always in progress.

Learn more biomedcentral.com/submissions 